\title{
Микропримеси в галените «красичных» жил Березовского месторождения, по данным LA-ICP-MS
}

\author{
Сидорова Н.В. ${ }^{1}$, Артемьев Д.А. ${ }^{2}$ \\ ${ }^{1}$ ИГЕМ РАН, Москва, nsidorova989@mail.ru \\ ${ }^{2}$ ИминУрО РАН, Миасc, daartemyev@gmail.com
}

Аннотация. В статье приведены новые данные по составу и распределению элементов-примесей в галените сульфидно-кварцевых «красичных» жил, полученные методом LA-ICP-MS. Количество основных элементов-примесей в галените $(\mathrm{Cu}, \mathrm{As}, \mathrm{Ag}, \mathrm{Cd}, \mathrm{Sn}, \mathrm{Sb}, \mathrm{Tl}, \mathrm{Te}, \mathrm{Bi})$ варьирует не только для разных жил, но и в пределах одной жилы. Особенностью галенита «красичных» жил стало неравное распределение в нем меди, сурьмы и золота. Золото выше предела обнаружения установлено в 12 из 32 проб и достигает 0.6 г/т. Прослеживается корреляция в парах Au-Ag 0.85, Au-Tl 0.8, Au-Bi 0.7. По всей выборке (n= 32) для пар Bi-Ag, Bi-Tl, $\mathrm{Ag-Tl}$ отмечена высокая степень корреляции $(\mathrm{r}=0.9)$. Золото может присутствовать в галените вместе с твердым раствором матильдит-миаргирит $\mathrm{AgBiS}_{2}-\mathrm{AgSbS}_{2}$.

Ключевые слова: Березовское месторождение, листвениты, галенит, золото, LA-ICP-MS.

\section{Trace elements in galena (LA-ICP-MS) of the «krassyk» gold-sulphide-quartz veins from the Berezovsk deposit}

\author{
Sidorova N.V. ${ }^{1}$, Artem 'ev D.A. ${ }^{2}$ \\ ${ }^{1}$ IGEM RAS, Moscow, nsidorova989@mail.ru \\ 2Imin RAS, Miass, aartemyev@gmail.com
}

\begin{abstract}
New data was obtained on the composition and distribution of trace elements in galena from the «krassyk» gold-sulphide-quartz veins. According to LA-ICP-MS analysis the content of trace elements in galena, such as $\mathrm{Cu}, \mathrm{As}, \mathrm{Ag}, \mathrm{Cd}, \mathrm{Sn}, \mathrm{Sb}, \mathrm{Tl}, \mathrm{Te}, \mathrm{Bi}$, varies in different veins and within the same vein. Specific feature of the galena from the «krassyk» veins is nonunifom distribution of copper, antimony and gold in ablation spectrums. Gold above the detection limit is found in 12 of the 32 samples and reaches $0.6 \mathrm{~g} / \mathrm{t}$. There is a positive correlation between Au-Ag 0.85, Au-Tl 0.8, Au-Bi 0.7. For the entire sample $(\mathrm{n}=32)$ a high degree of correlation was observed between $\mathrm{Bi}-\mathrm{Ag}, \mathrm{Bi}-\mathrm{Tl}$, and $\mathrm{Ag}-\mathrm{Tl}$ with the correlation coefficient $(\mathrm{r}=0.9)$. Gold may be present in galena together with a solid solution of mathildite-miargyrite $\mathrm{AgBiS}_{2}-\mathrm{AgSbS}_{2}$.
\end{abstract}

Key words:The Berezovsk Gold Deposit, listvenite, galena, gold, LA-ICP-MS.

Березовское месторождение расположено на Среднем Урале, в 12 км С-В от г. Екатеринбурга и представляет собой систему многочисленных даек гранитоидов $\left(\mathrm{C}_{3}\right)$ (субмеридиональных и ССВ), залегающих в метаморфизованных (ФЗС) вулканогенно-осадочных породах (O-S) с линзами и пластами гипербазитов (Бородаевский, Бородаевская, 1947; Прибавкин и др., 2012; Vikent'eva et. al., 2017). Золотосодержащими рудами являются сульфидно-кварцевые жилы и их зальбанды. Золотоносные жилы делятся на «лестничные» (полосовые) и «красичные». Первые приурочены к гранитоидным дайкам и ограничены контактами даек, вторые залегают во вмещающих зеленокаменных породах и серпентинитах, лиственитизированных около жил. «Красичные» жилы сульфидно-кварцевого состава залегающие вне даек, располагаются почти всегда группами (свитами) по 4-5 (иногда 10 и более) параллельных кулисно расположенных жил длиной каждая до 40, иногда 70-100 м. Расстояние между жилами от 3-5 до 10-15 м, а между свитами - до 1 км и более. Простирание и падение их аналогично жилам, залегающим в дайках, мощность жил варьирует в пределах 0.1-0.3 м, иногда достигает 0.5-1.0 м (Золоторудные..., 1984). Помимо основной золотоносной метасоматической формации на периферии Березовского месторождения, в центре Шарташского плутона, локально распространены метасоматиты гумбеитовой формации, также относящиеся к золотоносным (Спиридонов, 1997). Шарташский массив полого погружается под Березовское золоторудно-дайковое поле и в районе месторождения кровля массива располагается на глубине до 4 км. На глубоких горизонтах 

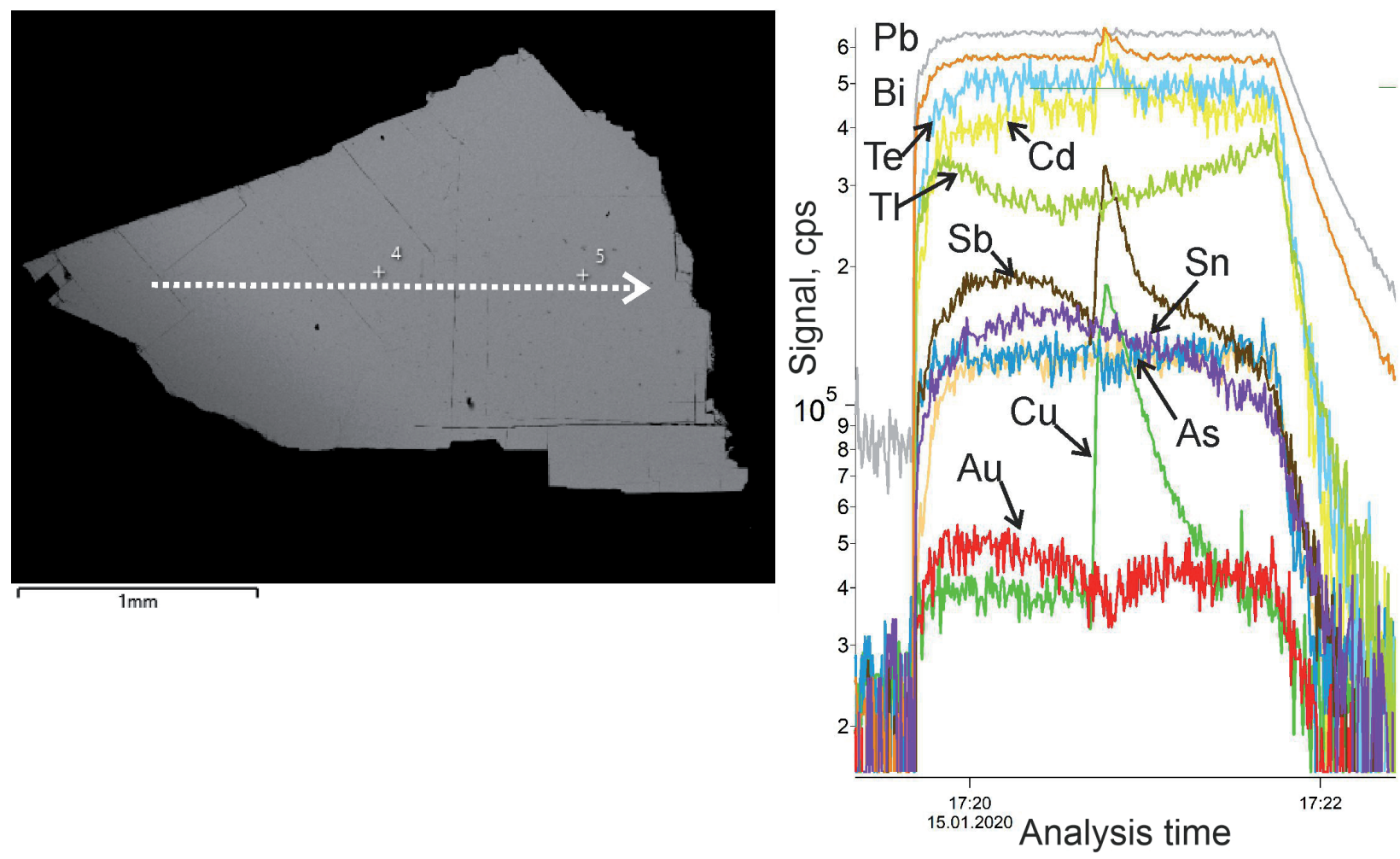

Рис. 1. BSE-изображение агрегата галенита с профилем абляции. Средние содержания элементов в области 4 (LA-ICP-MS, ppm): $\mathrm{Bi}-21300 ; \mathrm{Ag}-10010 ; \mathrm{Te}-216 ; \mathrm{Cd}-115 ; \mathrm{Tl}-15 ; \mathrm{Sn}-15 ; \mathrm{Sb}-33 ; \mathrm{Cu}-4 ; \mathrm{As}-52$; $\mathrm{Au}-0.6$; в области 5: $\mathrm{Bi}-20700 ; \mathrm{Ag}-9650 ; \mathrm{Te}-204 ; \mathrm{Cd}-126 ; \mathrm{Tl}-18 ; \mathrm{Sn}-10 ; \mathrm{Sb}-21 ; \mathrm{Cu}-12 ; \mathrm{As}-54$; $\mathrm{Au}-0.4$. Резкий пик $\mathrm{Bi}-\mathrm{Te}-\mathrm{Sb}-\mathrm{Cu}$ связан с прохождением профиля через микротрещину по спайности.

Fig. 1. BSE-image of galena aggregate with ablation profile. Average content of the impurity elements around the point 4 (LA-ICP-MS, ppm): $\mathrm{Bi}-21300 ; \mathrm{Ag}-10010$; Te - 216; Cd - 115; Tl - 15; $\mathrm{Sn}-15 ; \mathrm{Sb}-33 ; \mathrm{Cu}-4 ; \mathrm{As}-52$; $\mathrm{Au}-0.6$; around the point 5: $\mathrm{Bi}-20700 ; \mathrm{Ag}-9650 ; \mathrm{Te}-204 ; \mathrm{Cd}-126 ; \mathrm{Tl}-18 ; \mathrm{Sn}-10 ; \mathrm{Sb}-21 ; \mathrm{Cu}-12 ; \mathrm{As}-54$; $\mathrm{Au}-0.4$.The sharp peak of $\mathrm{Bi}-\mathrm{Te}-\mathrm{Sb}-\mathrm{Cu}$ is caused by penetration of the ablation profile in a cleavage microfracture.

Березовского месторождения описаны лиственитоподобные метасоматиты, отнесенные авторами к гумбеитовой формации (Спиридонов и др., 2014).

Применение современных прецизионных методов исследования минерального вещества (РСМА, ЛА-ИСП-МС) для повсеместно распространенных сульфидов (пирита, галенита и т.д.) золотоносных метасоматических формаций Березовского месторождения актуально для выяснения поведения микроэлементов при разных условиях рудообразования.

В предыдущих работах по изучению микросостава и распределения элементов-примесей в пирите методом LA-ICP-MS (Сидорова и др., 2019) было показано, что в целом пирит на месторождении имеет однотипный набор элементов примесей и характер их распределения. Исключением здесь стал золотоносный пирит, обнаруженный локально и, судя по всему, являющийся редкой находкой.

Галенит на месторождении можно отнести к повсеместно распространенным сульфидам, он развит по трещинам в агрегатах пирита в срастании с самородным золотом, блеклой рудой, халькопиритом, айкинитом, козалитом, а также слагает мономинеральные гнезда. Хотя вторым по распространенности рудным минералом в золотоносных жилах считается блеклая руда, в отобранных образцах «красичных» жил, местами, такое значение имел и галенит. Предпосылкой для сравнения состава галенита тыловых зон разных метасоматических колонок стало обнаружение неоднородного распределения $\mathrm{Cu}$, Sbи Au в галените сульфидно-кварцевых прожилков в гумбеитах Шарташского массива (Сидорова др., 2019).

Элементы-примеси в галените изучались с помощью лазерной абляционной системы NewWaveResearch UP-213 (США), сочлененной с квадрупольным масс-спектрометром Agilent 
7700x (AgilentTechnologies, США) в ИминУрО РАН (г. Миасс) (аналитик Д.А. Артемьев). Параметры съемки детально описаны в статье (Артемьев и др., 2017). Каждый анализ проводился прожиганием линии с диаметром лазерного пучка 100 мкм.

Для анализа методом LA-ICP-MS было выбрано 14 зерен галенита из 5 сульфидно-кварцевых «красичных» жил. В BSE-режиме зерна галенита однородные и не имеют видимых включений. При сопоставлении результатов СЭМ и ЛА-ИСП-МС выявлено, что количество основных элементов-примесей в галените (Cu, $\mathrm{As}, \mathrm{Ag}, \mathrm{Cd}, \mathrm{Sb}, \mathrm{Te}, \mathrm{Bi})$ варьирует не только для разных жил, но и в пределах одной жилы. Наряду с этим, перечисленные химические элементы можно отнести к изоморфным примесям в галените. Вариации содержаний «макрокомпонентов», в ppm: Ag 818-10010 при ср.геом. 1800; Вi 400-28300 при ср.геом. 2800; Те 90-1165 при ср.геом. 180. Остальные микропримеси, встречающиеся повсеместно (мин-макс/ср.геом., ppm): As 5-80/27; Cd 57-221/140; In 0.001-0.5/0.1; Sn 2-29/13; Sb 8-770/140; T1 1-18/2. Медь (0.5-840 при ср.геом. $8 \mathrm{ppm)} \mathrm{также} \mathrm{относится} \mathrm{к} \mathrm{повсеместно} \mathrm{встречающимся} \mathrm{примесям,} \mathrm{но} \mathrm{зачастую} \mathrm{её} \mathrm{распределение} \mathrm{в}$ галените неравномерное. Цинк обнаружен в половине проб в количестве от 0.4 до $32 \mathrm{ppm}$; селен - в $80 \%$ проб в количестве от 0.9 до $8.5 \mathrm{ppm}$. Золото выше предела обнаружения установлено в 12 из 32 проб и достигает 0.6 г/т.

Отличительной особенностью галенита «красичных» жил стало неравное распределение в нем меди, сурьмы и золота. Эта закономерность проиллюстрирована на рисунке 1 . По всей выборке $(\mathrm{n}=32)$ для пар Bi-Ag, Bi-Tl, Ag-Tl отмечена высокая степень корреляции (r=0.9). В галените с золотом прослеживается корреляция в парах $\mathrm{Au}-\mathrm{Ag} \mathrm{0.85,} \mathrm{Au-Tl} \mathrm{0.8,} \mathrm{Au-Bi} \mathrm{0.7,} \mathrm{при} \mathrm{общем} \mathrm{количестве}$ проб абляции 12. При этом в галените с содержанием золота на уровне предела обнаружения также наблюдалось неоднородное распределение меди.

Золото может присутствовать в галените вместе с твердым раствором матильдит-миаргирит $\mathrm{AgBiS}_{2}-\mathrm{AgSbS}_{2}$.

Подобный характер распределения золота был установлен галените из гумбеитов Шарташского массива (Сидорова др., 2019). Но здесь не было прослежено корреляционных связей Аu ни с какими микроэлементами, а высокие степени корреляционных отношений зафиксированы в парах $\mathrm{Cu}-\mathrm{Sb}$ 0.87, $\mathrm{Cu}-\mathrm{Ag} \mathrm{0.72,} \mathrm{Ag-Sb} \mathrm{0.89,} \mathrm{Bi-Tl} 0.71$ (n=33). Из чего сделано предположение, что неоднородное распределение $\mathrm{Au}, \mathrm{Cu}$ и $\mathrm{Sb}$ может быть связано с тонкодисперсными включениями бурнонита $\mathrm{CuPbSbS}$, поскольку последний является характерным и распространенным минералом гумбеитов и наличие которого могло способствовать осаждению субмикроскопического самородного золота. В галените лестничных жил золото диагностировано в редких пробах в виде дискретных пиков.

Таким образом, состав микропримесей и их распределение в галените «красичных» жил отличен от такового в галените лестничных жил, но имеет схожие черты в распределении золота с гумбеитовым галенитом.

Работа выполнена в рамках базовой темы и частично поддержана из средств грантов РФФИ (20-05-00849).

\section{Литература}

1. Артемьев Д.А., Масленников В.В., Филиппова К.А. Масс-спектрометрия с индуктивно-связанной плазмой и лазерной абляцией в минералого-геохимических исследованиях института минералогии УрО РАН // Металлогения древних и современных океанов. 2017. № 1. С. 201-206.

2. Бородаевский Н.И., Бородаевская М.Б. Березовское рудное поле. М. Изд-во: Металлургиздат. 1947. 264 с.

3. Золоторудные месторождения. Т. 1 (Европейская часть СССР). Ред. Бородаевская М.Б., Бородаевский Н.И. М. Изд-во: ЦНИГРИ. 1984. 291 с.

4. Прибавкин С.В., Монтеро П., Беа Ф., Ферштатер Г.Б. U-Pb возраст пород и оруденения Березовского золоторудного месторождения (Средний Урал) // Труды института геологии и геохимии им. Академика А.Н. Заварицкого. 2012. №159. С. 211-217.

5. Сидорова Н.В., Викентьев И.В., Абрамова В.Д., Ковальчук Е.В. Золото и другие элементы-примеси в пирите Березовского месторождения, Средний Урал // Литосфера. 2019. Т. 19. № 2. С. 327-336. 
6. Сидорова Н.В., Ковригина С.В. О неоднородности состава галенита гумбеитов Шарташского массива, Березовское рудное поле, Средний Урал // Металлогения древних и современных океанов. 2019. № 1. C. 178-181.

7. Спиридонов Э.М., Бакшеев И.А., Середкин М.В., Куруленко Р.С., Прокофьев В.Ю., Устинов В.И., Прибавкин С.В., Филимонов С.В. Гумбеитовая формация Урала. М. Изд-во: Геологич. ф-т МГУ. 1997.100 с.

8. С Сиридонов Э.М., Сидорова Н.В., Нурмухаметов Ф.М., Коротаева Н.Н., Куликова И.М., Поленов Ю.А., Трошкина А.Н. Лиственитоподобныеапопикритовыефлогопит-магнезитовыегумбеитыБерёзовского месторождения золота с цирконом, монацитом, ксенотимом, фторапатитом, турмалином, реликтовым цинкохромитом // Уральский геологический журнал. 2014. № 1 (97). С. 20-67.

9. Vikent'eva O.V., Bortnikov N.S., Vikentyev I.V., Groznova E.O., Lyubimtseva N.G., Murzin V.V. The Berezovskgiantintrusion-related gold-quartz deposit, Urals, Russia: Evidence for multiple magmatic and metamorphic fluid reservoirs // Ore Geol. Rev. 2017. V.91.P. 837-863. https://doi.org/10.1016/j.oregeorev.2017.08.018. 